\title{
DIALLEL CROSS IN PLANT BREEDING
}

N. E. G. GILBERT

John Innes Horticultural Institution, Bayfordbury, Hertford, Herts.

Received 12.ii.58

A DIALLEL cross consists of all possible crosses between a number of varieties. Reciprocal crosses, and the selfed parents, may or may not be omitted. Such a set of crosses is obviously of interest to the plant breeder, but the information obtained may not be worth the trouble of making the cross. In this paper the utility of such crosses is considered, using data available in the literature together with some new figures from an $18 \times 18$ cross in tomatoes.

The statistical analysis of a diallel cross has been described by Yates (1947). It consists of fitting additive main effects for parents, and their interactions in the individual crosses. Such a main effect is sometimes called "general combining ability " or " additive genetical component" while an interaction may be referred to as "specific combining ability" or "non-additive genetical component". The word interaction is used here in its purely statistical sense of a departure from additivity. It should not be confused with any form of genetical interaction between postulated "genes". The interactions are part of the statistical description of the data, being the ups and downs which remain when the main effects have been taken out. The analysis is similar to that of factorial experiments, and merely assumes that the contributions of male and female parents are equally important. The exact mode of inheritance is not specified, and the analysis would be as effective for, say, blending inheritance as for Mendelian. There is no need for the parents to be inbred (or to have a uniform coefficient of inbreeding). It may be objected that a plant breeder is interested in, say, the top $2 \frac{1}{2}$ per cent. of each progeny, and so wishes to estimate not the mean $\mu$ but $\mu+2 \sigma$ where $\sigma$ is the standard deviation. This, however, involves an adjustment in practice and not in principle. In many cases there will not be enough replication to give useful estimates of $\sigma$ for each particular cross and heterogeneity of variance will be undetectable. Main effects can, however, be fitted for log variance or standard deviation in the same way as for progeny means. This factorial method of analysis is to be judged by its success in describing the data.

\section{THE “POLYGENE" ANALYSIS}

A second method of analysis, based on ideas introduced in the classical paper of Fisher (I9I8) and developed by Fisher, Immer and Tedin (1932) and Mather (1949), has been put forward by Jinks and Hayman (I953), Jinks (I 954) and Hayman (I954b). It involves the assumption, inter alia, that the yield (or whatever character is being 
analysed) is controlled by a number of genes with additive effects, which may show dominance and interaction between loci. These genes are individually unrecognisable; the analysis is concerned with their combined action as revealed by the various statistics. Now, no analysis is of any direct use to the practical breeder unless it causes him in some way to alter his breeding programme for the better. Before starting any experiment in any field of inquiry, the questions at issue and the relevance of the information to be gained should be clearly and explicitly stated. It is not at all clear how the " polygene" analysis can help the breeder in a specific problem since, even accepting the genetical assumptions and statistical methods employed, it is not known which plants contain which genes. Further knowledge of the genetics of continuous variation in general would, of course, be beneficial to all plant breeding.

The concepts of dominance, epistacy and so on are more complex in polygene analysis than in Mendelian genetics. For example, a study of the known genes in Drosophila (Bridges, 1944), maize (Weijer, I952) and tomato (Rick and Butler, 1956) shows that non-lethal genes nearly always show complete dominance or (as in blood groups) complete independence, although Haldane (1954) points out that homozygotes and heterozygotes that are macroscopically indistinguishable may show quantitative biochemical differences. In polygene analysis the possibility of lethality is ignored and dominance is taken to mean any departure of the effect of $\mathrm{A} a$ from the average of the effects of AA and aa. As Mather (1949) has shown, a change of scale can convert "semi-dominance" into neutrality or recessiveness. This vagueness is the fault, not of the analysis itself, but of the difficulties arising from the nature of the data. But the consequences are, first, that the genetic labels such as dominance or complementarity are easily confused in the results obtained in practice (Hayman, I954b) and, second, that alternative genetical systems characterised by, e.g. purely multiplicative gene effects could be analysed in the polygene way in terms of additive gene effects and their various types of interaction, i.e. dominance, epistacy, etc. The idea of additive independent gene effects-treating departures from this simple scheme as genic interaction-is employed solely because it leads to simplicity in the statistical analysis. Other hypotheses, e.g. multiplicative gene action, would be equally acceptable genetically. There is thus a danger of accepting this convenient working hypothesis as a paragon, and supposing that the genetics of continuous variation must necessarily be viewed in this way. One can say "the situation can be explained thus" but not "the situation evidently must be explained thus and not otherwise". In qualitative genetics Mendelism is supreme and cases such as that of Irwin (1947), where a hybrid gives a product qualitatively different from that of either parent, appear to be rare. No such all-embracing scheme has yet been found in quantitative genetics. This is not to say, of course, that Mendelism is inapplicable 
here ; there can be no doubt that it is applicable. But the mathematical applications of Mendelism so far tried have not been completely successful in producing a clear-cut picture. The general picturee.g. the fraction of the observed variation which may reasonably be dubbed "genetical "- should turn out to be much the same whatever the genetical hypothesis, but the details will depend on the particular hypothesis used. In practical breeding work, therefore, it should not be supposed that the idea of additive gene action is an absolute way of looking at the situation, although it may well give as good a description as any. But even in an ideal situation in which it was certain that the system behaved-and would go on behavingaccording to the additive hypothesis, the results of the polygene analysis of a diallel cross appear to have no relevance to the practical problems of the breeder. They would not help him decide what to do next. This does not, of course, affect the validity of such analysis as a tool in pure genetics; but the analysis is also open to criticism on both genetical and statistical grounds. There is no reason why valid statistical methods should not be used, but the genetical objections are not easily disposed of.

The genetical assumptions are (Hayman, r954b) :

(i) Diploid segregation

(ii) No difference between reciprocal crosses

(iii) Independent action of non-allelic genes

and in the diallel cross

(iv) No multiple allelism

(v) Homozygous parents

(vi) Genes independently distributed between the parents.

In his discussion Hayman shows that a failure of assumption (ii) can be dealt with and that assumption (iv) is unimportant until the $\mathrm{F}_{2}$ but that failure of any of the others leads to trouble. He makes the recommendation-remarkable to a statistician-that should a statistical test (that in his notation the regression of $\mathrm{Wr}$ on $\mathrm{Vr}$ must be linear and of unit slope) fail, particular lines may be removed from the diallel cross until the remnant does satisfy this test. This procedure has been disputed by Kempthorne (1956) on the ground that, if the original set of parents is regarded as a random sample from some larger population, the reduced set of parents cannot be so regarded. This objection loses its force when a breeder is concerned only with the particular parents involved. This same point must be made about Griffing's (1956a) demonstration, following Fisher, that the inclusion of selfs as well as crosses causes bias. But the principle that, if a set of data contradict some limited hypothesis, the offending parts of the data may be removed and the analysis completed on the remainder, is debatable. It is usually thought better to reject the hypothesis as it stands. It might at least be expected that the significance levels employed when testing the remnant should be made 
more stringent-following the usual probability laws-to allow for the selection that has been practised on the data. The gravity of this matter can be seen from the statement of Jinks (1954) that in one case an $8 \times 8$ cross was reduced to a $5 \times 5$. The results of such selective analysis cannot be supposed to have any wider, inductive application except to material that has been similarly selected.

The same objection applies to Hayman's alternative recommendation that a particular progeny may be disallowed, and missing-plot technique used to replace it, in order that the data may fit the hypothesis. The "missing plot" is merely a device to facilitate the analysis of an otherwise difficult (because incomplete) set of data and should not be used to replace egregious and unwelcome (but perfectly genuine) observations.

Assumption (i) of diploid segregation is usually perfectly justified. However, endosperm (which makes up the greater part of the yield of cereals) is triploid and in fact about one-third of the genes in a grain of maize are not derived from the plant on which it grew at all. Material of one genotype grows on a plant of another. The phenomenon of Xenia is well known for Mendelian characters; whether it applies to yield is unknown. This point is unimportant to Yates' (1947) method of analysis of first-order statistics but is relevant to Jinks and Hayman's (1953) analysis of second-order statistics of the yield of maize (or any other cereal). It is, however, a small point; at best the pollen " rain" will be uniform over the whole experiment, and there will merely be a small increase in the error component. Incidentally, it is not clear whether Kinman and Sprague (1945), from whom Jinks and Hayman derive their data, are reporting total ear weight or yield of shelled corn. This does not affect the present argument much since the corn contributes about $\frac{6}{7}$ of the weight of an ear of maize (Griffing and Lindstrom, 1954).

In biochemical gene action there must be some kind of negative feed-back to give stability of development. The only alternative is that each gene can make only a fixed amount of its product between divisions. Gene interaction cannot be avoided at the biochemical level and so assumption (iii) dealing with the phenotypic level, must be purely empirical. It can be tested and may be found to give an adequate description of the ultimate gene effects on size of plant. Assumption $(\mathrm{v})$ is a consequence of inbreeding in the absence of inversions or other chromosomal devices for the maintenance of heterozygosity, when this is selectively advantageous to the plant.

Assumption (vi) is impossible except in trivial cases. For example, if in a $10 \times 10$ cross 3 parents are AA (and $7 a a$ ), and 8 parents are BB (and $2 b b$ ) then it is assumed that exactly 2.4 parents are AA BB. It is not clear to what extent the inevitable departures from this assumption are tolerable.

The mathematical consequences of failure of assumptions (ii), (iii), (iv) and (v) have been explored by Dickinson and Jinks (1956), 
Kempthorne (1956) and Matzinger and Kempthorne (1956). These papers are interesting as theory. It is evident that, while it is quite possible to sort out the various kinds of interaction between the postulated "additive" genes, data that could genuinely do so would have to be much more extensive than any so far published. Once interaction between loci is established, the value of the concept of discrete additive genes is reduced. Kempthorne points out that assumption (vi) remains crucial, and he insists that the parents must be the result of unselected inbreeding from a random mating population. This ensures the approximate satisfaction of assumption (vi), although it is not strictly necessary to it. It is hard to think of any other justification for making such an assumption.

Now it might be asserted that such genetical assumptions are only made in order to obtain a simple working hypothesis (as is done in any statistical analysis of any type of data), and that the important point is whether the hypothesis fits the data. The way in which, in this case, the data are made to fit the hypothesis has been criticised above. By making a seventh assumption, of equality and absence of oppositions in the dominance effects of the various genes, it is possible to estimate the number of loci involved. Of the results of such estimation Jinks (1954) remarks "It would appear from these results that the basic assumptions on which this estimation is based are far from being realised in the present data and for that matter in any other data so far analysed by these methods." The failure of this seventh assumption alone would not invalidate the rest of the analysis, but it is not clear why it should necessarily be the seventh assumption that is blamed. This estimate of the number of genes is critical because, if there is any point in it at all, it must give a commonsense answer; whereas the other parameters estimated may reasonably take almost any values.

\section{STATISTICAL METHODS}

The least squares estimation procedure proposed by Jinks (1956) is open to criticism on grounds of statistical efficiency. The matter has been discussed by Mather (1949) and by Nelder (1953). Fisher (1928) showed that the use of inefficient estimates produces misleading results and it is unusual to give such estimates unless it is certain that the loss of information is small. Efficient estimation (e.g. by maximum likelihood) is not impossible, although certainly more troublesome in this case than least squares. This objection does not apply to the analysis of $F_{1}$ 's only since estimation is then by equation of observation to expectation.

A more serious matter is the regression of $\mathrm{Wr}$ on $\mathrm{Vr} . \mathrm{Vr}$ is the estimated variance of the set (or "array") of all crosses involving the $r^{\text {th }}$ parent (including that parent selfed). Wr is the covariance of the array with the corresponding parents. Obviously $\mathrm{Wr}$ and $\mathrm{Vr}$ do not fulfil the assumptions about independence and normality which are basic to regression analysis. 
Hayman's (1954b) use of $\mathrm{Wr}+\mathrm{Vr}$ to determine the order of dominance of the parents needs to be justified by the previous demonstration of overall heterogeneity in the values of $\mathrm{Wr}+\mathrm{Vr}$. Since $\mathrm{Wr}$ is statistically correlated with $\mathrm{Vr}$ a suitable though approximate procedure would be to test Vr for heterogeneity by Bartlett's (1937) test. (Although the Vr's are not statistically independent, because each cross contributes to two of them, this test still gives satisfactory results, at any rate for values of $k$ exceeding 6 .)

Thus although "polygene" analysis should not be dismissed out of hand, the greatest possible circumspection should be used when considering its results. Theory is liable to outrun performance.

\section{PRACTICAL RESULTS}

I shall now take such data as are available and see what answers they give to a number of questions of interest to the breeder. These data are derived mainly from tomatoes and maize, both of which exhibit hybrid vigour. Heterosis in the inbreeding tomato is not of the same magnitude as in outbreeding maize, but it cannot be neglected by the breeder. Neither can it be ignored by the statistician, and so the $\mathrm{F}_{1}$ 's have been analysed separately from the parents throughout. The term $F_{1}$ is here used to distinguish the crosses from the parents: it does not necessarily imply that the parents were completely inbred. Since reciprocal crosses are not represented, the analysis is in essence that of the diagonal sums in section 2 of Yates (1947), with some extensions. The numerical results on which the conclusions are based are summarised in the Appendix.

(i) Is it helpful to describe the data in terms of main effects and interactions, and do such interactions occur?

This question is answered by means of the analysis of variance. In a $k \times k$ diallel cross (omitting reciprocals) with each progeny replicated $r$ times, let $y_{12}=$ the sum (over $r$ plots) for the cross of parent $\mathrm{I} \times$ parent 2 , and $\mathrm{Y}_{1}=$ the sum (over $(k-\mathrm{I}) r$ plots) of all the $(k-1) y$ 's which involve parent $\mathrm{r}$. Then the analysis of variance of $\mathrm{F}_{1}$ 's only runs :

\begin{tabular}{|c|c|c|c|}
\hline & & d.f. & S.S. \\
\hline Parents (main effects) & . & $k-1$ & $\frac{\operatorname{dev}^{2} Y}{r(k-2)}$ \\
\hline Interactions & . & $\frac{1}{2} k(k-3)$ & by difference \\
\hline Between $F_{1}$ 's & . & $\frac{1}{2} k(k-1)-1$ & $\frac{\operatorname{dev}^{2} y}{r}$ \\
\hline
\end{tabular}


Here "dev" " means as usual "sum of squares about the mean". An error S.S. is derived as usual from replication of the parents and $F_{1}$ 's. If the "main effects" mean square does not exceed the " interactions" M.S., the main effects are useless for predicting the yields of individual crosses and the concept of general combining ability is unhelpful. If the "interactions" M.S. exceeds the error M.S. then, however useful the main effects may be, they are not completely successful in prediction. In practice main effects provide an apt way of describing the behaviour of the crosses, but interactions do occur. This means that parents with relatively small main effects cannot be expected to contribute to a high-yielding cross. In the $18 \times$ I 8 cross, for example, many of the I 53 interactions were "significant" but none was so large as to ruin completely the prediction from main effects for that particular cross. But it does not follow that the two parents with the largest main effects will necessarily combine to give the best cross ; for they may show a negative interaction, or another cross may show a large positive interaction. It may turn out (as in fertiliser trials) that main effects are more constant from year to year than interactions, but there is as yet insufficient evidence on this point.

\section{(ii) Do main effects give better prediction of $F_{1}$ yields than a regression on the mid-parent?}

The "mid-parent" is the mean of the yields of the two parents concerned. Let $\mathrm{P}_{1}=$ the sum (over $r$ plots) for parent I. The calculation of the regression of $y_{12}$ on $\left(\mathrm{P}_{1}+\mathrm{P}_{2}\right)$ can be shortened by using the algebraic identities $\operatorname{dev}^{2}\left(\mathrm{P}_{1}+\mathrm{P}_{2}\right)=(k-2) \operatorname{dev}^{2}\left(\mathrm{P}_{1}\right)$ and $\mathrm{S} y_{12}\left(\mathrm{P}_{1}+\mathrm{P}_{2}\right)=\Sigma \mathrm{Y}_{1} \cdot \mathrm{P}_{1}-\frac{(\Sigma \mathrm{Y})(\Sigma \mathrm{P})}{k}$. This sum of products may also be used in estimating the correlation between main effects and parental yields, but I shall not do so here because the correlation as such is less pertinent to the breeder than questions (ii) and (iii) under discussion. The variance of the $\frac{1}{2} k(k-I) y$ 's is then split up in the usual way into I d.f. for regression and $\frac{1}{2} k(k-1)-2$ d.f. remainder. The "regression" component is in fact part of the "main effects" S.S. in (i), being orthogonal to the "interactions" S.S. If the "remainder" M.S. turns out to be consistently smaller than the "interaction" M.S., then regression gives better prediction than the main effects. In practice it does not.

It can be argued that the main effects $(t)$ have an error variance $\frac{\sigma^{2}}{(k-2) r}$ whereas the P's, being the total of only $r$ plots, are less accurately estimated. This purely statistical difference can be corrected for (approximately) by subtracting $\frac{(k-\mathrm{I})(k-3) r s^{2}}{k-2}$ from $\operatorname{dev}^{2} \mathrm{P}$, where $s^{2}$ is the error M.S. When reciprocals are included in the experiment, the main effects have error variance $\frac{\sigma^{2}}{2(k-2) r}$ and the 
correction to $\operatorname{dev}^{2} \mathrm{P}$ is $\frac{(k-1)(2 k-5)}{2(k-2)} r s^{2}$. A regression analysis carried out with this corrected value of $\operatorname{dev}^{2} \mathrm{P}$ will allow for this statistical difficulty, although it cannot be expected to follow the mathematical theory of regression exactly. This does not matter much here, where the problem is not to estimate a regression coefficient but to see whether the superiority of the main effects for prediction is merely due to their superior accuracy of estimation. In practice it is not.

(iii) Within the limits of experimental error, do the main effects correspond to the parental yields, or are some parents more potent when crossed than would be expected from their own yields?

This question overlaps question (ii) and is not of great practical value in individual experiments since a breeder is interested in the magnitude of the main effect as such rather than its relation to the parent yield. But it is of interest when considering the general utility of the diallel cross. Since $y_{12}=m+t_{1}+t_{2}+t_{12}$ (where $m$ is the general mean, $t_{1}, t_{2}$ are main effects and $t_{12}$ the interaction), it follows that the difference between $y_{12}$ and its mid-parent is

$$
m+\left(t_{1}-\frac{p_{1}}{2}\right)+\left(t_{2}-\frac{p_{2}}{2}\right)+t_{12}
$$

where $p$ is the parental mean. The question is therefore whether the values of $(t-p / 2)$ are heterogeneous. To answer this, the value of $2 \mathrm{Y}-(k-2) \mathrm{P}$ is found for each parent. Then $\frac{\operatorname{dev}^{2}[2 \mathrm{Y}-(k-2) \mathrm{P}]}{\left(k^{2}-4\right) r}$ is a " heterogeneity of potence" S.S. with $(k-1)$ d.f. Its mean square can be compared with the error M.S. When reciprocals are included in the experiment, this expression becomes $\frac{\operatorname{dev}^{2}[\mathrm{U}-(k-2) \mathrm{P}]}{k(k-2) r}$ (Hayman I954a) where $\mathrm{U}$ corresponds to $\mathrm{Y}$ but is now the sum of $2(k-\mathrm{I}) r$ plot-observations. In practice such heterogeneity of potence does occur, and is of the same order of magnitude as the interactions (but not the main effects). This heterogeneity is unpredictable in that the regression of main effect on parental mean does not, on the average, differ from $\frac{1}{2}$. Now if the answers to questions (ii) and (iii) had been negative, there would be no point in bothering about main effects at all since the yields of the parents themselves would do as well. But the present results mean that quite apart from the matter of interaction, the diallel cross does contribute information that cannot be obtained from the parents as such; but this additional information is not equal in importance to the parental yields. To paraphrase a famous quotation, like begets like; but some are more like than others. 
(iv) The relation between $F_{1}$ and $F_{2}$

In one case (section I of the Appendix) figures are available for $F_{1}$ and $F_{2}$. It is of course uncertain whether the relationship between the data of the two generations in this particular case will be found to be a general one. The relation between $F_{1}$ and $F_{2}$ has been ably discussed by Hayman (1957). Although that paper is couched in polygene terms, it is primarily concerned with first-order statistics (means) rather than with second-order (variances and covariances). This means not only that the methods employed are more reliable from a purely statistical point of view, but that they do not in fact require all the assumptions usually involved in polygene analysis. They would be adopted by those who favour a more cautious and pragmatic approach such as is advocated here. The technical considerations relevant to first- and second-order statistics have been discussed by Nelder (1953). Further $\mathbf{F}_{2}$ material is reported by Jinks (1956), but I have not been able to analyse his (unpublished) original data in this alternative fashion.

It is not surprising to observe a reduction in the average size of the interactions in the $F_{2}$ (as measured by the mean square). The correlation between corresponding $F_{1}$ and $F_{2}$ interactions is small but positive $(r=0.255,34$ d.f. $)$. The regression of $\mathbf{F}_{2}$ main effects on parental means and $F_{1}$ main effects gives

$$
\mathrm{F}_{2} \text { main effect } \simeq 0.4 \mathrm{I}\left(\frac{1}{2} p\right)+0.53 t
$$

and does not differ significantly from the expected $\frac{1}{2}\left(\frac{1}{2} p+t\right)$. Such expected main effects are almost as good as the estimated $F_{2}$ main effects for predicting the relative yields for $F_{2}$ progenies :

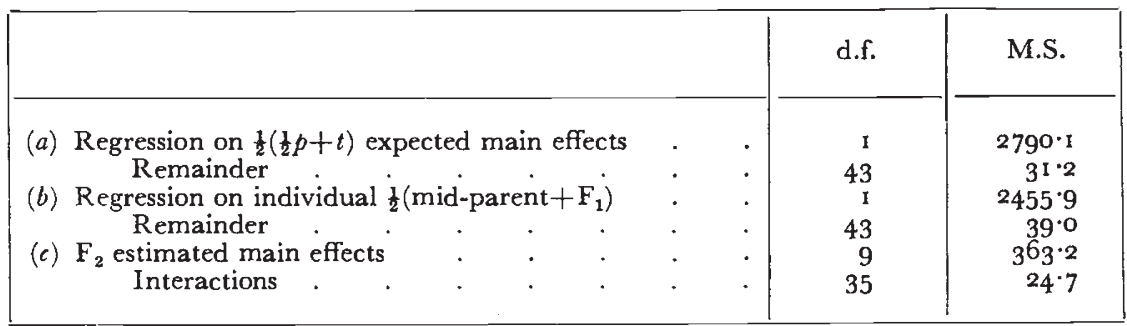

The complete diallel cross is, in fact, more likely to be worthwhile in the investigation of such relationships between generations in continuous variables than in a breeding programme as such. If the number of parents involved is large enough to interest the breeder, the number of possible crosses reaches a formidable total and some device for reducing the amount of work involved may become necessary.

\section{FRACTIONAL REPLICATION}

It appeared above that in practice the main effect, or general combining ability, cannot be predicted exactly from the parental mean. Furthermore, the parents themselves give no information 
about the possibilities of heterosis. The breeder may therefore wish to estimate the main effects of a set of $k$ varieties without making all the $\frac{k(k-1)}{2}$ possible crosses. An obvious course is to use three or four control varieties and cross them with all the experimental ones. This is wasteful if the control varieties are of no direct interest to the breeder, since each cross contributes information about one main effect only (instead of two) and the interactions obtained are valueless. In the more likely case when the "control" varieties are in fact experimental material, the "control" main effects are very well estimated and the others poorly. It is possible to make a more balanced experiment at the price of a more complicated statistical analysis.

Complete balance is unobtainable; that is to say, unless every cross is grown, the differences between the various main effects will not all be estimated with equal accuracy. But the discrepancies will not be very serious if the number of crosses to which each parent contributes is constant. It is not difficult to satisfy this condition. The problem is connected with a particular type of Latin square : or alternatively it may be considered as that of arranging $k$ varieties in incomplete blocks of two plots each. If $k$ is divisible by 4 , the simplest solution is given by a $k \times k$ Latin square symmetrical about both diagonals; e.g. for $k=8$, the upper half of a square such as

$\begin{array}{lllllllllllllllll}\mathrm{h} & \mathbf{a} & \mathbf{b} & \mathbf{c} & \mathbf{d} & \mathbf{e} & \mathbf{f} & \mathbf{g} & \mathrm{or} & \mathrm{h} & \mathbf{a} & \mathbf{b} & \mathbf{c} & \mathbf{d} & \mathbf{e} & \mathbf{f} & \mathbf{g} \\ \mathrm{a} & \mathrm{h} & \mathbf{g} & \mathbf{b} & \mathbf{e} & \mathbf{d} & \mathbf{c} & \mathbf{f} & & \mathrm{a} & \mathrm{h} & \mathbf{c} & \mathbf{b} & \mathbf{e} & \mathbf{d} & \mathbf{g} & \mathbf{f} \\ \mathrm{b} & \mathrm{g} & \mathrm{h} & \mathbf{a} & \mathbf{f} & \mathbf{c} & \mathbf{d} & \mathbf{e} & & \mathrm{b} & \mathrm{c} & \mathrm{h} & \mathbf{f} & \mathbf{a} & \mathbf{g} & \mathbf{d} & \mathbf{e} \\ \mathrm{c} & \mathrm{b} & \mathrm{a} & \mathrm{h} & \mathbf{g} & \mathbf{f} & \mathbf{e} & \mathbf{d} & & \mathrm{c} & \mathrm{b} & \mathrm{f} & \mathrm{h} & \mathbf{g} & \mathbf{a} & \mathbf{e} & \mathbf{d} \\ \mathrm{d} & \mathrm{e} & \mathrm{f} & \mathrm{g} & \mathrm{h} & \mathbf{a} & \mathbf{b} & \mathbf{c} & & \mathrm{d} & \mathrm{e} & \mathrm{a} & \mathrm{g} & \mathrm{h} & \mathbf{f} & \mathbf{b} & \mathbf{c} \\ \mathrm{e} & \mathrm{d} & \mathrm{c} & \mathrm{f} & \mathrm{a} & \mathrm{h} & \mathbf{g} & \mathbf{b} & & \mathrm{e} & \mathrm{d} & \mathrm{g} & \mathrm{a} & \mathrm{f} & \mathrm{h} & \mathbf{c} & \mathbf{b} \\ \mathrm{f} & \mathrm{c} & \mathrm{d} & \mathrm{e} & \mathrm{b} & \mathrm{g} & \mathrm{h} & \mathbf{a} & & \mathrm{f} & \mathrm{g} & \mathrm{d} & \mathrm{e} & \mathrm{b} & \mathrm{c} & \mathrm{h} & \mathbf{a} \\ \mathrm{g} & \mathrm{f} & \mathrm{e} & \mathrm{d} & \mathrm{c} & \mathrm{b} & \mathrm{a} & \mathrm{h} & & \mathrm{g} & \mathrm{f} & \mathrm{e} & \mathrm{d} & \mathrm{c} & \mathrm{b} & \mathrm{a} & \mathrm{h}\end{array}$

is superimposed on the possible crosses

$$
\begin{aligned}
& \begin{array}{lllllll}
\text { I2 } & \text { I3 } & \text { I4 } & \text { I5 } & \text { I6 } & \text { I7 } & \text { I8 }
\end{array} \\
& \begin{array}{llllll}
23 & 24 & 25 & 26 & 27 & 28
\end{array} \\
& \begin{array}{lllll}
34 & 35 & 3^{6} & 37 & 3^{8} \\
& & & & \\
\text { etc., }
\end{array}
\end{aligned}
$$

and each parent occurs once in the four crosses picked out by any letter of the Latin square. If $k$ is even, but not divisible by 4 , similar designs without the same degree of symmetry are easily found; for $k=6$ the only three complete solutions are

$\begin{array}{llllllllllll}\mathrm{f} & \mathbf{a} & \mathbf{b} & \mathbf{c} & \mathbf{d} & \mathbf{e} & \mathrm{f} & \mathbf{a} & \mathbf{b} & \mathbf{c} & \mathbf{d} & \mathbf{e} \\ \mathrm{a} & \mathrm{f} & \mathbf{e} & \mathbf{b} & \mathbf{c} & \mathbf{d} & \mathrm{a} & \mathrm{f} & \mathbf{c} & \mathbf{d} & \mathbf{e} & \mathbf{b} \\ \mathrm{b} & \mathrm{e} & \mathrm{f} & \mathbf{d} & \mathbf{a} & \mathbf{c} & \mathrm{b} & \mathrm{c} & \mathrm{f} & \mathbf{e} & \mathbf{a} & \mathbf{d} \\ \mathrm{c} & \mathrm{b} & \mathrm{d} & \mathrm{f} & \mathbf{e} & \mathbf{a} & \mathrm{c} & \mathrm{d} & \mathrm{e} & \mathrm{f} & \mathbf{b} & \mathbf{a} \\ \mathrm{d} & \mathrm{c} & \mathrm{a} & \mathrm{e} & \mathrm{f} & \mathbf{b} & \mathrm{d} & \mathrm{e} & \mathrm{a} & \mathrm{b} & \mathrm{f} & \mathbf{c} \\ \mathrm{e} & \mathrm{d} & \mathrm{c} & \mathrm{a} & \mathrm{b} & \mathrm{f} & \mathrm{e} & \mathrm{b} & \mathrm{d} & \mathrm{a} & \mathrm{c} & \mathrm{f}\end{array}$


and the mirror image of the second square about its second diagonal. Incomplete solutions are also possible, e.g.

$\begin{array}{ccccc}\text { a } & d & \text { b } & \text { d } & \text { c } \\ & c & d & b & d \\ & & a & d & b \\ & & & c & d \\ & & & & a\end{array}$

where each parent occurs once in $a, b, c$ but twice in the set $d$ which cannot be split up into two single sets. If $k$ is odd, each parent must be represented an even number of times. Different sets of crosses in which each parent occurs twice may be found for any value of $k$ by writing down the parents in order and taking consecutive pairs; thus

and $\quad \begin{array}{llllllll} & \mathrm{I} & 2 & 3 & 4 & 5 & \text { gives } \mathrm{r} 2,23,34,45,5 \mathrm{r} \\ & 3 & \mathrm{r} & 4 & 2 & 5 & \text { gives } & 3 \mathrm{r}, \mathrm{r} 4,42,25,53\end{array}$

The statistical analysis of such an incomplete diallel cross involves the solution of a fairly tractable set of non-orthogonal least squares equations. Thus for $k=6$ the set of crosses 12, 13, 14, 24, 25, 35, $36,46,56$ gives least squares and reciprocal matrices

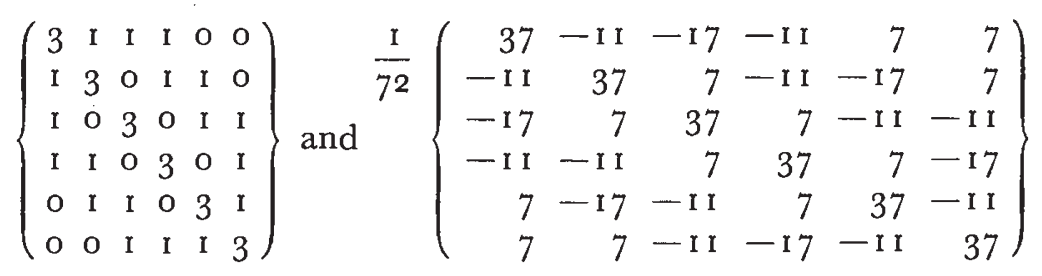

This idea of fractional replication is not so useful as it may appear at first sight. The omission of some crosses will result in an alteration in the estimated main effects, due to the interactions of the omitted crosses. This will not, however, invalidate the fractional replicate since the interactions are less important than the main effects. (If this were not the case, the concept of main effects and interactions would have to be abandoned.) The fractional replicate merely offers a rational solution to the problem of a breeder who wishes to grow some exploratory crosses without making all possible crosses. The main effects can then be used to give expectations for the missing crosses, but clearly it would be better to grow all crosses if possible.

\section{CONCLUSIONS AND SUMMARY}

The diallel cross offers a means of rationalising some aspects of plant breeding while keeping the amount of work down to a manageable level. Its utility to the breeder can be exaggerated. The polygene analysis of a diallel cross suffers from several theoretical defects, but in any case its results do not appear to be directly relevant to practical breeding work. The performance of the parental varieties themselves 
gives valuable prediction of the relative behaviour of the crosses, but the diallel cross does give further information. Whether it might be used for assessing long-term potentialities of raw material at the beginning of a long brecding programme is unknown.

A brecder faced with a mass of material would do well to make an ordinary varicty trial to discover the best 15 or 20 lines. He might then employ these as parents in a fractional diallel cross with each parcnt represented in perhaps 8 crosses. Alternatively, he might eliminate more parents on the basis of their performance as varieties and then makc, say, a complete ro $\times$ io cross. In either case, the results would permit the selection of a few parents for intensive work. This is, of course, a naive idealisation of a breeder's position, but shows that the diallel cross can be used to advantage in the later stages of selection. No statistics can replace the breeder's intimate knowledge of his crop : but they can help.

Acknoweledgments. - I wish to thank Dr F. Yates, F.R.s., and Mr Watkin Williams for their valuable criticism of statistical and plant breeding aspects. The opinions expressed here are, of course, my own.

\section{REFERENCES}

ALLARD, R. W. 1956. Estimation of prepotency from Lima bean diallel cross data. Agron. $\mathcal{F} ., 4^{8}, 537-543$.

Bartlett, м. s. 1937. Properties of sufficiency and statistical tests. P.R.S., A, I6o, $268-282$.

BRIDGES, C. B. 1944. The Mutants of Drosophila melanogaster. Washington : Carnegie Institution.

CURRENCE, T. M., LARSON, R. E., AND VIRTA, A. A. I944. A comparison of six tomato varieties as parents of $F_{1}$ lines resulting from the fifteen possible crosses. P:oc. Amer. Soc. hort. Sci., 45, 349-352.

DICKINSON, A. G., AND JINKs, J. L. 1956. A generalised analysis of diallel crosses. Genetics, $4 I, 65-78$.

FISHER, R. A. 1918. The correlation between relatives on the supposition of Mendelian inheritance. Trans. roy. Soc. Edinb., 52, 399-433.

FISHER, R. A. 1928. Statistical Methods for Research Workers. 2nd Ed. Oliver and Boyd, Edinburgh.

FISHER, R. A., IMMER, F. R., AND TEDIN, O. 1932. The genetical interpretation of statistics of the third degree in the study of quantitative inheritance. Genetics, I7, $107-124$.

GRIFFING, B. 1956a. A generalised treatment of the use of diallel crosses in quantitative inheritance. Heredity, $10,31-50$.

GRIFFING, B. $1956 b$. Concept of general and specific combining ability in relation to diallel crossing systems. Aust. F. biol. Sci., 9, 463-493.

GRIFFING, B., AND LINDSTROM, E. W. 1954. A study of the combining abilities of corn inbreds having varying proportions of corn belt and non-corn belt germ plasm. Agron. J., 46, 545-552.

HALDANE, J. B. S. 1954. The Biochemistry of Genetics. Allen and Unwin, London.

HAYMAN, B. I. I954a. The analysis of variance of diallel tables. Biometrics, ro, 235-244.

hayman, B. 1. 1954b. The theory and analysis of diallel crosses. Genetics, 39, 789809 .

hayman, B. I. 1957. Interaction, heterosis and diallel crosses. Genetics, 42, 336-355- 
HORNER, T. W., AND LANA, G. P. 1957. A three-year study of general and specific combining ability in tomatoes. Proc. Amer. Soc. hort. Sci., 69, 378-387.

IRWIN, M. R. I947. Immunogenetics. Advanc. Genet., I, I33-I 59.

JINKs, J. L. 1954. The analysis of continuous variation in a diallel cross of Nicotiana rustica varieties. Genetics, 39, 767-788.

Jinks, J. L. 1956. The $\mathrm{F}_{2}$ and backcross generations from a set of diallel crosses. Heredity, Io, I-30.

jinks, J. L., AND hayman, B. I. 1953. The analysis of diallel crosses. Maize Genetics Co-op. Newsletter, 27, 48-54.

KEMPTHORNE, O. 1956. The theory of the diallel cross. Genetics, $4^{I}, 45^{1-459}$.

KINMAN, M. L., AND SPRAGUe, G. F. 1945. Relation between number of parental lines and performance of synthetic varieties of corn. 7. Amer. Soc. Agron., 37, $34 \mathrm{I}-35^{\mathrm{I}}$.

MATHER, K. 1949. Biometrical Genetics. Methuen, London.

MATZINGER, D. F., AND KEMPTHORNE, O. 1956. The modified diallel table with partial inbreeding and interactions with environment. Genetics, ${ }_{4} I, 822-833$.

NELDER, J. A. 1953. Statistical models in biometrical genetics. Heredity, 7, I I-I I9. PoWers, L. 1945. Relative yields of inbred lines and $F_{1}$ hybrids of tomato. Bot. Gaz., I06, 247-268.

Rick, C. M., AND BUtler, L. 1956. Cytogenetics of the tomato. Advanc. Genet., $8,267-382$.

ROJAS, B. A., AND SPRAGUE, G. F. 1952. A comparison of variance components in corn yield trials. III. General and specific combining ability and their interaction with locations and years. Agron. F., 44, 462-466.

SPRAGUe, G. F., AND TATUM, L. A. 1942. General versus specific combining ability in single crosses of corn. J. Amer. Soc. Agron., 34, 923-932.

WEIJER, J. 1952. A catalogue of genetic maize types. Bibliogr. Genet., I4, 189-425. YATES, F. 1947. Analysis of data from all possible reciprocal crosses between a set of parental lines. Heredity, I, 287-30r.

\section{APPENDIX}

Those parts of the numerical analyses relevant to the discussion are reproduced here in a condensed form. They include

(i) The analysis of variance of $F_{1}$ 's by main effects, interactions and error (where available).

(ii) The analysis of variance of $\mathrm{F}_{1}$ 's by regression on the mid-parents $(a)$ as they stand and $(b)$ correcting for the inferior accuracy of parental yields compared with the main effects.

(iii) The mean square for heterogeneity of potence.

I. Kinman and Sprague (1945). Yield of inbred parents, $F_{1}$ and $F_{2}$ in maize. $k=\mathrm{I}$ o, $r=\mathrm{I}$.

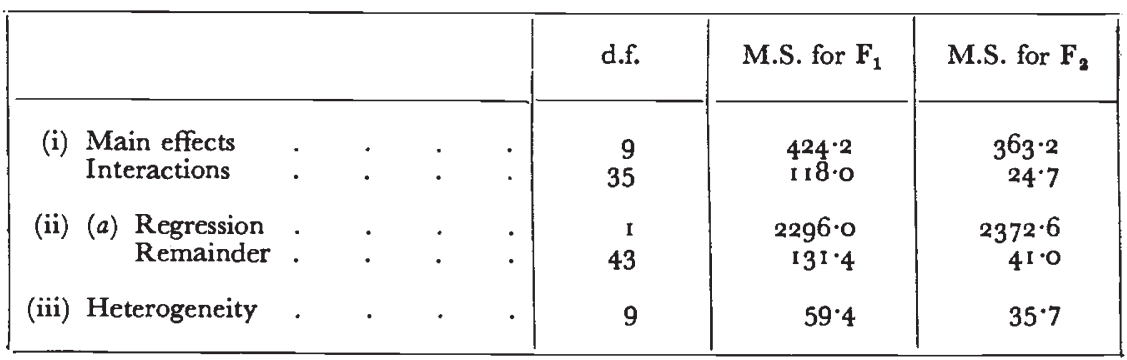


2. Griffing and Lindstrom (1954). Ear weight and shelled corn weight in maize. $k=9, r=6$. Part of this analysis has been presented by Griffing (1956b.) The parents were randomised separately from the $F_{1}$ 's, but this does not invalidate the present analysis.

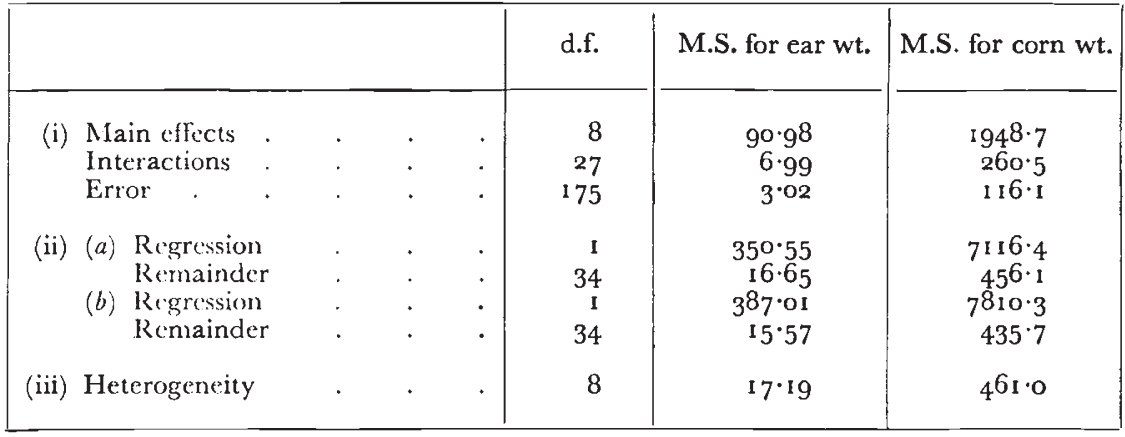

3. Allard $(19 j 6)$. Seed-size of lima beans. $k=9, r=5$. The experimental layout was not randomised, so that the estimate of error is not strictly valid and progeny means may be biased.

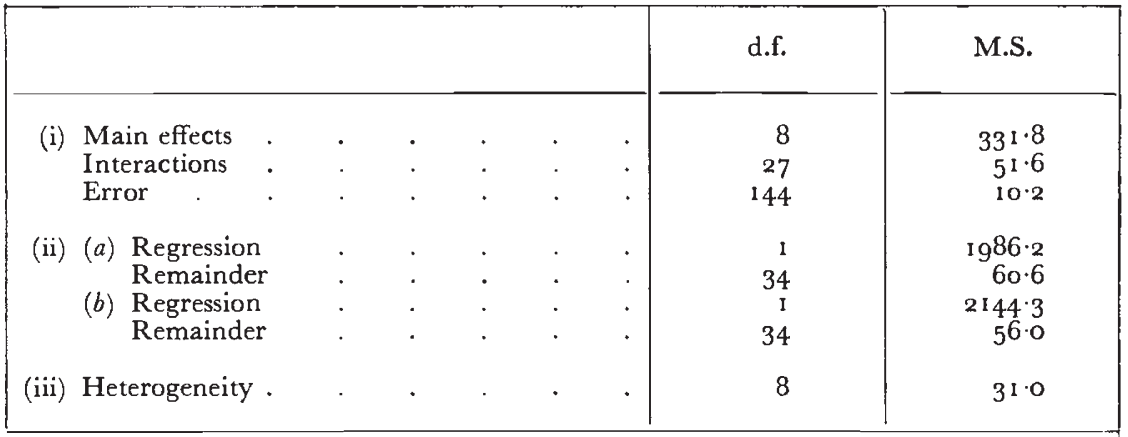

4. Hayman (1954). Flowering date of Nicotiana rustica. $k=8, r=2$. Reciprocals were included and the following analysis is of reciprocal sums (and differences) as described by Yates (1947).

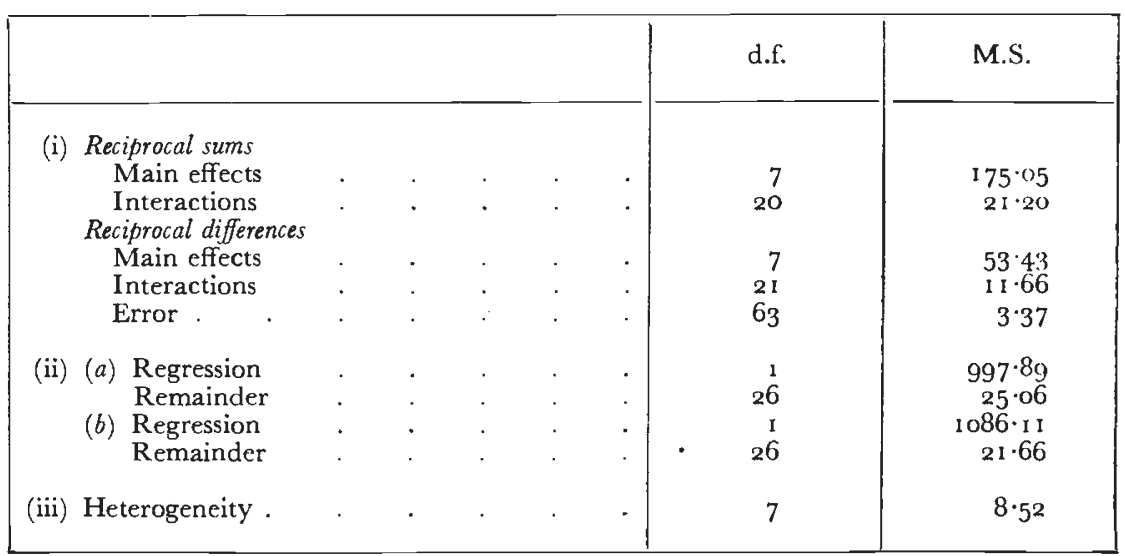


5. Jinks (1954). Plant height of Nicotiana rustica. $k=8, r=2$. Parents and $F_{1}$ reported for two successive years. Means of reciprocals are given, and the error is estimated from reciprocal differences, not replication. This estimate of error appears to be on a per-plot basis and is quoted here as such.

\begin{tabular}{|c|c|c|c|c|c|c|}
\hline & & & & d.f. & M.S. Ist year & M.S. 2nd year \\
\hline (i) & $\begin{array}{l}\text { Main effects } \\
\text { Interactions } \\
\text { Error }\end{array}$ & . & . & $\begin{array}{r}7 \\
20 \\
56\end{array}$ & $\begin{array}{r}\text { I01 } 4 \cdot 67 \\
59 \cdot 61 \\
2 \cdot 49\end{array}$ & $\begin{array}{r}902 \cdot 27 \\
43 \cdot 80 \\
7 \cdot 71\end{array}$ \\
\hline (ii) & $\begin{array}{ll}\text { (a) Regression } \\
\text { Remainder } \\
\text { (b) Regression } \\
\text { Remainder }\end{array}$ & : & . & $\begin{array}{r}1 \\
26 \\
1 \\
26\end{array}$ & $\begin{array}{r}566 \text { r } \cdot 64 \\
\text { IOI } \cdot 28 \\
5820 \cdot 38 \\
91 \cdot 79\end{array}$ & $\begin{array}{r}4606 \cdot 11 \\
99 \cdot 46 \\
4975 \cdot 64 \\
85 \cdot 24\end{array}$ \\
\hline (iii) & Heterogeneity & . & . & 7 & $91 \cdot 12$ & $80 \cdot 23$ \\
\hline
\end{tabular}

6. Currence, Larson and Virta (1944). Yield of tomatoes. $k=6, r=2$.

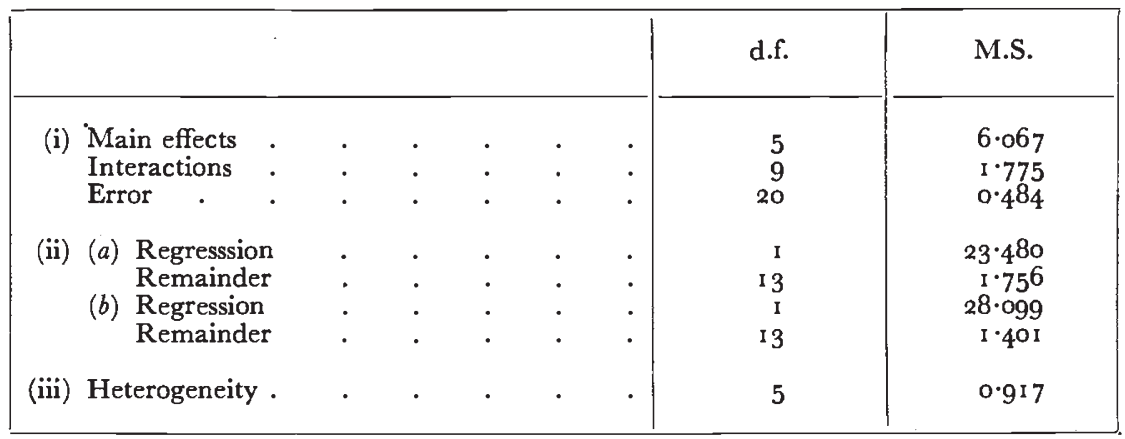

7. Powers (1945). Yield of tomatoes. $k=10, r=10$. Data for seven characters of less importance to the breeder are also given.

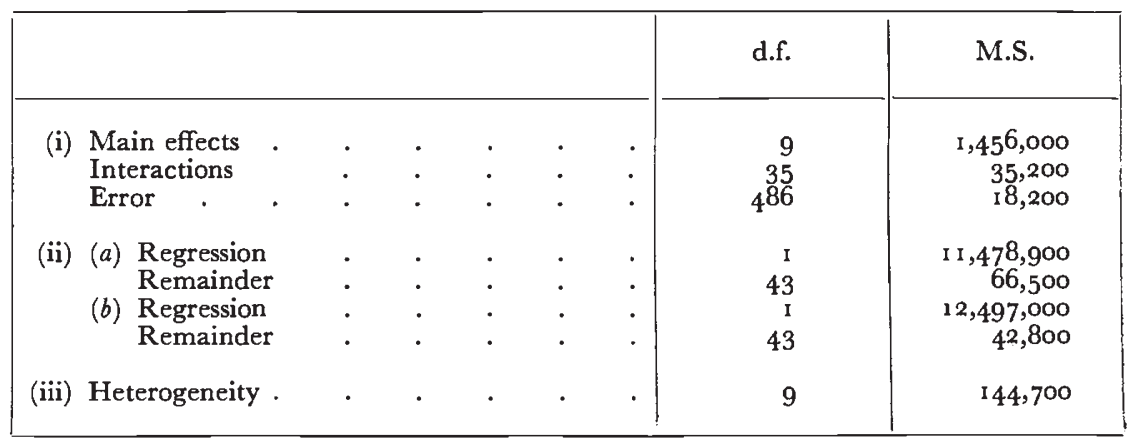


8. English commercial varieties of tomatoes. $k=18, r=6$.

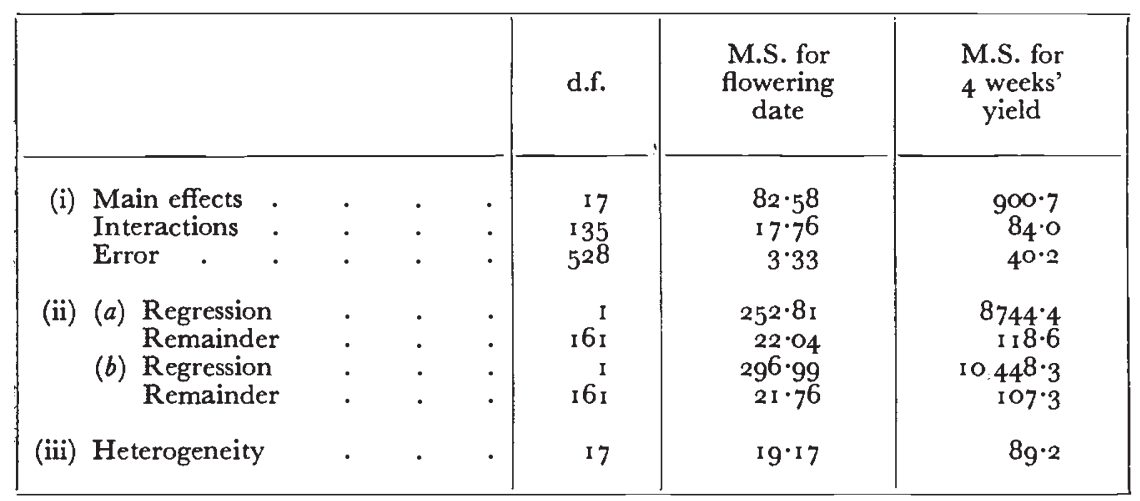

9. Statistics (variance components) derived from numerous analyses of variance (i) are quoted by Sprague and Tatum (1942) and Rojas and Sprague (1952) for maize and by Horner and Lana (1957) for tomatoes. These figures show the same general features as those quoted here. 